\title{
Isaac Peral y la navegación submarina a través de la prensa gaditana (1887-1891)
}

\section{JOAQUIN M PIÑEIRO BLANCA}

Desde el mes de abril de 1887 hasta el de enero de 1891, un asunto de gran interés, y muy llamativo, llenaba las primeras páginas de la prensa gaditana: el teniente de navío Isaac Peral y Caballero, profesor entonces de la Academia de Aplicación de San Fernando, había proyectado un modelo de torpedero submarino que, según la opinión de los entendidos en la materia de aquel entonces, era "la última palabra en el arte naval militar" (1). Peral había presentado ante el Ministerio de Marina, en 1885, una memoria en la que desarrollaba su proyecto de submarino para la defensa de la península, las Baleares y las Canarias. La memoria es aprobada. Dos años más tarde, la Gaceta de Madrid publica un Real Decreto por el que se establece la construcción, con carácter de urgencia, del buque submarino proyectado en el Arsenal de La Carraca (2). El primer paso se había dado. A su regreso de Madrid, Peral es recibido en la estación del ferrocarril de San Fernando de un modo apoteósico, en una clara muestra de orgullo ante los posibles éxitos del invento y ante las repercusiones positivas que ello tendría para la ciudad. El entusiasmo provocado es, además, asimilable con mayor facilidad si tenemos en cuenta que estamos en una época en la que los "inventos" todavía eran considerados como posibles "salvaciones de la humanidad".

Pocos días después de su llegada a San Fernando, Peral se dispuso a notificar a la Reina Regente, María Cristina de Habsburgo, el inicio de la construcción del submarino y las posibles ventajas que, en caso de éxito, conllevaría "para equilibrar nuestro poder marítimo con el de otras naciones de mayores recursos" (3). Asimismo se mencio-

(1) Diario de Cádiz, 24 de abril de 1887.

(2) Diario de Cádiz, 25 de abril de 1887.

(3) Diario de Cádiz, 26 de abril de 1887. 
nan las posibles vías de subvención; el coste iba a resultar pequeño, y sería necesario, para reafirmar el carácter español del invento, que fuese construido en su totalidad en España, y, desde luego, con materiales nacionales. Los trabajos dieron comienzo en el Arsenal de La Carraca el 23 de octubre de 1887; diez meses después el submarino estaba prácticamente concluido.

La prensa gaditana recoge con júbilo la próxima botadura del "invento". Como las máquinas propulsoras se encontraban ya construidas, se anunció de manera insistente la brevedad con que se iniciarían las primeras pruebas con el "nuevo y originalísimo" buque tras su lanzamiento. Un periodista gaditano describió así el submarino, tras una visita efectuada al Arsenal (4): "De imaginarse el volumen del casco por sus dimensiones conocidas, al contemplarlo construido, existe notable diferencia. No es un juguete o modelo de un arma de guerra menor, es un buque, como si dijéramos, hecho y derecho, y muy digno de respeto en razón a las especialísimas condiciones que reúne como arma ofensiva. En el interior la vida será mucho más llevadera que en los torpederos corrientes, y sus tripulantes tendrán mayor facilidad en los movimientos (...). No es tampoco una tiritaña, como algunos suponían, las planchas del aforro, que tienen espesor de un centímetro, de tal manera cosidas y con tan sólidas y profusas trabazón de quilla, cuadernas y puntales, que lo hacen más fuerte y resistente que otros buques de porte mucho mayor".

La confianza existente con respecto al éxito del submarino proyectado por Peral era indudable. Constantemente se aludía a su gran seguridad, a la agilidad de maniobra, e incluso a su aspecto estético: "Aquello no es un trabajo de herreros, es lo que se llama un bordado, que hace honor a los operarios de La Carraca y al maestro Sr. Santamaría, que los dirige en tan primorosa y difícil tarea".

A pesar de haber sido anunciada para la primera quincena de agosto, la botadura no se efectuó hasta el nueve de septiembre de 1888 (5). Como era constumbre en esta época, el Arsenal se "engalanó" profusamente con gallardetes, farolillos, banderas y guirnaldas de flores. En el muelle se preparó una capilla de arquitectura efímera, en la que se colocó como exorno el frontal de plata regalado a La Carraca en tiempos de Carlos III. Frente a ésta se levantó un templete de madera "de mucho arte" destinado a las autoridades militares. "La cha-

(4) Diario de Cádiz, 19 de julio de 1888.

(5) Diario de Cádiz, 9 de septiembre de 1888. 
ranga del Arsenal dejó oír los acordes de la marcha real, y las campànas sus acentos de bronce, en tanto que los marineros daban cumplimiento a las órdenes del Sr. Peral; botándose el torpedero, que se deslizó rápida y seguramente sobre los raíles, entrando en el agua majestuosa $\cdot y$ gallardamente". El buque quedó sumergido sólo hasta el centro del cilindro ojival, viéndose así cumplidos los cálculos de Souto.

Auque se había prometido rapidez en el inicio de las pruebas pertinentes, éstas no se efectuaron hasta el verano de 1889. La incertidumbre creada en torno a su posible inicio fue creciendo de modo progresivo según iba avanzando el tiempo. Las esperanzas depositadas en el invento estaban basadas en ideas tales como que una flota de estos buques dotarían a España de unos medios de defensa tan poderosos, que colocarían a la nación en el puesto glorioso que había disfrutado en el pasado. Digamos que el submarino de Peral se había constituido en el símbolo de las aspiraciones españolas (o al menos, de las aspiraciones de un determinado grupo de españoles). Esta creciente inquietud motivó que el propio Peral accediese a ser entrevistado por la prensa gaditana, aunque esto le incomodase, a fin de poder satisfacer, en parte, la curiosidad de todos (6). Como la confianza de éxito del autor del proyecto era tan grande o mayor que la de los que se interesaban por êl, en lugar de hablar de las inminentes pruebas, expuso sus planes a largo plazo. Éstos eran los de la construcción de una flota de cuarenta submarinos, el número necesario, según sus cálculos, para una buena defensa de las costas. Como los torpederos debían moverse con electricidad, proyectó el establecimiento de una serie de estaciones eléctricas para la carga de sus acumuladores. Estas debían establecerse en Cádiz, Ceuta, Cartagena, Barcelona, Mahón, Ferrol, Bilbao y Pasajes. Además de dos "de segunda clase" en Valencia y Vigo, "sólo para casos fortuitos".

Peral, minucioso siempre en sus cálculos, manifestó que estas estaciones eléctricas costarian sesenta y cinco mil pesetas las de primera clase y treinta y cinco mil las de segunda. Este bajo costo era asimismo compartido por los buques submarinos: cada uno de ellos no sobrepasaría las trescientas mil pesetas, de modo que, con aproximadamente doce millones y medio de pesetas, "tendría España un armamento formidable". Para resaltar la gran ventaja que suponía esta cifra, se la hizo entrar en comparación con los cuarenta millones de pesetas que costaba, en aquel entonces, un acorazado. A todos estos datos

(6) Diario de Cádiz, 8 de febrero de 1889. 
unió el del número de hombres que serían necesarios para mantener la nueva flota: un comandante, tres oficiales, tres individuos de maestranza y cinco marineros por submarino. En total resultarían unos seiscientos hombres para la dotación de los cuarenta buques, una cifra que fue considerada poco elevada y muy ventajosa. Ya hemos apuntado que las esperanzas puestas en el proyecto fueron muchas, pero esta expectación se vio pronto rota: en marzo de 1889 (7), se anunció una "excursión" del submarino por la bahía. Los gaditanos, fuertemente impulsados por la curiosidad, comenzaron a llenar las murallas desde primeras horas, creándose un ambiente casi festivo. Desde la Alameda hasta Puertas de Tierra, todas las azoteas de las casas situadas en primer plano se hallaban también abarrotadas de vecinos. Muy pronto todos se verían desilusionados al anunciarse que el submarino había sufrido "un pequeño accidente" que obligó a suspender la prueba preparada. La siguiente en organizarse se vio igualmente truncada, tuvo lugar pocos días después (8). En esta ocasión la bahía se llenó de embarcaciones repletas de un público dispuesto a presenciar ese "acontecimiento histórico" en primera fila. En el vapor "Península", en la fragata "Carmen" y en el "María Gracia", "Ketty" y "Garibaldi" se organizaron en cubierta unos banquetes que contaron con "un menú excelente y unos vinos amontillado y manzanilla servidos con profusión entre los expedicionarios". Todas las personalidades civiles y militares se hallaban presentes. La salida del buque submarino del Arsenal de La Carraca, bajo el mando del propio Peral, se efectuó sin ningún contratiempo. Éste llegó a las proximidades del vapor "Península" entre los vítores de todos los que se hallaban en las cubiertas de las embarcaciones que rodeaban y seguían al submarino. "Peral tuvo que saludar con la gorra en la mano para corresponder a los aplausos de que era objeto, mostrando una gran emoción su esposa, quien tenía fijos los ojos en su marido como dándole ánimos, siendo una escena de gran emoción que sobrecogió los corazones de cuantos allí estaban". Sin embargo, todo este "glorioso acontecimiento" se vio pronto deslucido, con gran desilusión de todos los presentes. Después de estar detenido una media hora, durante la cual todos los asistentes se preguntaron una y otra veż por la causa de aquello, se supo que había surgido un inconveniente: la hélice de babor se había recalentado por

(7) Diario de Cádiz, 3 de marzo de 1889.

(8) Diario de Cádiz, 7 de marzo de 1889. 
un defecto de construcción, por lo que Peral estimó la suspensión para evitar mayores desperfectos, disponiéndose a regresar al Arsenal. El "Península" fue el encargado de remolcar el submarino.

Las pruebas se suspendieron hasta el mes de julio (9). En esta ocasión ya no fueron rodeadas del boato y carácter festivo de las dos anteriores, habían resultado ser dos golpes demasiado duros contra las esperanzas puestas en el proyecto. Consecuentemente las precauciones se extremaron (el submarino no debía alejarse de la costa) y la noticia de las pruebas se mantuvo en secreto, al menos oficialmente, ya que cierto público llenó las murallas y el muelle de Cádiz. Partiendo de la Casería de Ossio, y sin abandonar la línea de costa, llegó al muelle gaditano y bordeó la Punta de San Felipe. En esta ocasión la prueba de velocidad resultó un completo éxito, lamentándose la circunstancia de que no se hubiese podido realizar ante un público numeroso.

La siguiente efectuada, constituyó una nueva decepción. En septiembre, ante una buena parte del vecindario, repartido por el muelle y en botes y vapores, el submarino salió por los caños hacia la bahía, en medio de una densa niebla. A la altura de la Punta de la Cicla, el navío varo, quedando atrapado en el fango, siendo inútiles cuantos esfuerzos se hicieron para sacarlo de allí. El problema se agravó con la marea baja. El "Reina Cristina", por medio de cabos, sacó el buque de su atolladero horas después. El submarino navegó luego con entera normalidad, comprobándose que ninguno de sus mecanismos habían sido dañados por el percance (10).

Una vez superadas, a pesar de la gran cantidad de problemas sufridos, las pruebas de navegación en superficie y de velocidad, se decidió afrontar las correspondientes a inmersión. La primera se efectuó en noviembre, frente a la Punta de San Felipe. Los resultados fueron positivos: el submarino, sin perder la horizontalidad, giró suavemente antes de hundirse, y su marcha debajo de la superficie fue regular. Por teléfono, los tripulantes de los botes que rodean el buque proporcionan las cifras del fondeaje, rectificando el sondeo. También se les hace saber estos resultados por medio de un cartón blanco escrito, mostrándolo a través de los cristales del submarino. Este tardó una hora y cuarenta minutos en hacer la inmersión completa (a una profundidad de seis metros). Para confirmar los buenos resultados de la primera, se decidió efectuar otra inmersión completa, siendo ésta

(9) Diario de Cádiz, 18 de julio de 1889.

(10) Diario de Cádiz, 4 de septiembre de 1889. 
igualmente positiva. Estas pruebas se esgrimieron como "argumentos preciosos para los incrédulos o impacientes" y se calificaron como las últimas "glorias nacionales" (11). Aplausos y vivas a España, a Peral y a la tripulación del navio arroparon la salida del buque a la superficie. Pocos días después se llevó a cabo una nueva prueba de inmersión en el mismo lugar, causando las mismas reacciones exaltadas: "la bandera nacional que ondeaba elegante en la torrecilla, al sumergirse y volver a aparecer, pegada al palo, había perdido su esbeltez y airosa majestad, pero sin embargo, jamás ha podido producir el estandarte castellano más hondo e intenso sentimiento que en este nuevo aspecto" (12). Las pruebas de disparos de torpedos se organizaron para pocos días más tardes, resultando éstas positivas (13).

Las primeras felicitaciones y agasajos oficiales pronto se dejaron sentir: la Reina Regente recibe la propuesta del Capitán General del Departamento Marítimo de Cádiz, a través del Ministro de Marina, de la concesión de la Cruz al Merito Naval. También se elevan peticiones de condecoración para el resto de los tripulantes (14).

Las siguientes pruebas con las que debía enfrentarse el buque submarino constituían una de las más arriesgadas de entre las que se debían organizar: la navegación bajo agua en alta mar. La primera de ellas tuvo lugar seis meses más tarde que las descritas anteriormente, en junio de 1890 (15). Hacia el oeste se recorrieron unas cuarenta millas, en las que se invirtieron unas diez horas. La tripulación manifestó a su llegada a puerto que la nave en marcha no sufría ninguna clase de movimiento, y que la claridad que procedía de la superficie les permitió hasta leer y escribir sin el uso de la luz eléctrica. Detalles de este tipo nos muestran hasta que punto era grande la curiosidad que todo este asunto, tan novedoso para todos, había despertado en los gaditanos.

La siguiente prueba preparada constituyó la última y la más espectacular de todas ellas: el crucero "Colón" simularía un ataque a la plaza de Cádiz, situándose a tiro de cañón de ésta. El "Peral" defendería la costa y, sumergiéndose y acercándose al crucero, intentaría disparar contra él (16). El simulacro se hizo de noche. Esto no fue obstáculo para que no faltara el público en aquellos puntos de la ciudad en que únicamente se divisaban las luces de los buques que habían de tomar parte en la prueba. En el muelle, murallas y Alameda se

(11) Diario de Cádiz, 30 de noviembre de 1889.

(12) Diario de Cádiz, 5 de diciembre de 1889.

(13) Diario de Cádiz, 16 de diciembre de 1889.

(14) Diario de Cádiz, 17 de diciembre de 1889.

(15) Diario de Cádiz, 8 de junio de 1890.

(16) Diario de Cádiz, 22 de junio de 1890. 
advertía un movimiento no acostumbrado de personas para tan altàs horas de la noche. Los resultados finales de esta prueba fueron considerados los concluyentes: el "Peral" consiguió, sin ser visto, acercarse cuatro veces al "Colón", una de ellas a diez metros de distancia; y no fue divisado, a pesar de que navegó con la torre y parte del lomo en superficie. Se organizó un nuevo simulacro a la luz diurna en la mañana siguiente, en él la táctica a seguir era la de espera: cuando el "Colón" intentara situarse a tiro de plaza y divisara una pequeña parte de la torrecilla del submarino, se alejaría, y por tanto, de haber sido un buque enemigo, los cañonazos no hubiesen podido llegar a la ciudad.

En enero de 1891, Isaac Peral se traslada a Madrid para rendir cuentas ante el ministro de Marina de los excelentes resultados de todas las pruebas que se habían acordado efectuar sobre el buque submarino para comprobar con la práctica sus cualidades teóricas (17). La entrevista supuso una dura decepción para Peral: por una serie de confusas presiones, su proyecto fue finalmente rechazado. Se esgrimió como razón fundamental que el submarino no resultaba factible al tener que salir a la superficie para poder torpedear. Se le brindó que hiciese las reformas que él mismo creyese necesarias en su buque, a lo que se negó. Acto seguido se le ofreció otra solución: que construyese otro buque submarino, aprovechando los materiales del primero, bajo la inspección de una junta facultativa. Tampoco ésto fue aceptado por Peral, que, en estos mismos días, decide pedir la baja de la Armada, la cual le fue concedida. Ese mismo año, 1891, se marcha de España, y en el exilio permaneció hasta su muerte en 1895, a los cuarenta y cuatro años de edad. Un triste e imprevisible final para una historia que había comenzado bajo los auspicios más prometedores (18).

(17) Diario de Cádiz, 10 de enero de 1891.

(18) Para la realización de este estudio se han utilizado exclusivamente fuentes hemerográficas. De las disponibles para el caso de Cádiz, se ha elegido la serie del "Diario de Cádiz" por ser la que contaba con una mayor cobertura informativa sobre el tema objeto de análisis.

Para una mayor información sobre Peral y su proyecto de buque submarino, remito a la siguiente bibliografía:

-BARCENA, G.: Peral y su barco. Madrid, 1891.

-CAMUÑEZ, S.: Una página para la bistoria de San Fernando. Peral y Caballero. El Heraldo de San Fernando, 20 de octubre de 1926.

-GONZALEZ-ALLER HIERRO, J.: "Los programas navales de la Restauración". El buque en la Armada española. Madrid, 1981. pp. 307-357.

—GONZALEZ DE ALEDO, G.: "El Isaac Peral". Nuestra Marina: mares, barcos, bombres. Madrid, 1988. pp. 116-122.

-HERNANDEZ DEL POZO, L.: "El submarino: Monturiol y Peral". Historia de las Fuerzas Armadas. Barcelona, 1984. Tomo II. pp. 230-231.

-MADARIAGA, J. de: Submarino Peral. Madrid, 1889.

-PERAL, A.: El profundo Isaac. Madrid, 1934.

-PEREZ, D.: Isaac Peral. La tragedia del submarino Peral. Madrid, 1940.

-RODRIGUEZ GONZALEZ, A.: Política naval de la Restauración (1875-1898).Madrid, 1988. 